\title{
Some Thoughts about the Personalization Research Guidance of Postgraduate
}

\author{
Yang $\mathrm{Da}^{1, \mathrm{a}}$ \\ ${ }^{1}$ School of Jilin Agricultural University, Jilin 130000, China \\ ayangnan1983116@163.com
}

Keywords: Postgraduate education, personalization, research guidance, role definition

\begin{abstract}
There are a lot of researches about personalization research guidance in present. But those theories mostly talk about the education system and management of postgraduate. There are less theories which mention the specific role of supervisor in the process of guiding and training of postgraduate personalization. The article puts forward some corresponding views in order to solve some practical problems between supervisor and postgraduate in the process of personalization research guidance.
\end{abstract}

\section{Introduction}

From the view of the progress of human society, the role of undergraduate is inheritance and usage of knowledge. The education of postgraduate is the highest level of education system. It is the key link in innovative talent's cultivation and undertakes an important task of cultivating innovative talents. Along with the change of social era, the traditional elite's education mode also needs the enrollment expansion of postgraduate under the situation of diversified needs for social change. The training schemes of postgraduate have also revised in many colleges and universities. Each university follows the principle of optimizing the allocation of resources, improving the culture conditions, promoting interdisciplinary and promoting the sharing of high quality resources, they optimize the discipline structure, highlight the characteristics of discipline and improve teaching efficiency. The university provides a better environmental condition for the innovation research of postgraduate, meet the needs of economic construction and social development for high-level talents of all types and levels, the university should break the simple education and teaching mode of postgraduate. They should try to train postgraduates according to their aptitudes, pay attention to play the individual and special skills of postgraduates and create ways for the cultivation of innovative talents. To give the training of personalization and diversity for those students who have personality, specialty or special talent to adapt to the needs of talent market.

\section{The Purpose and Meaning of Personalization Research Guidance}

For the education of postgraduate, supervisor is one side of management. The education also need to inspire and mobilize the initiative of student. Then to ask postgraduate establish clear objectives and long-term career plans. The implementation effect of personalization program of postgraduate depends on the both sides of education- supervisor and postgraduate. Supervisor and postgraduate in the implementation process of plan should have their own roles. Supervisor's character, behavior, vision, academic thinking and analysis ability and so on various aspects can give the impression to postgraduate. Some influences are very important to the development and growth of postgraduate. The supervisor system training of postgraduate is essentially a hope that through this way influence postgraduate.

Personalization research guidance of postgraduate is that supervisor gives a kind of personalization guidance according to academic interests, knowledge structure and ability level of postgraduate in the process of research and maximize the subjective initiative and creativity of postgraduate. At the same time, the process of research training of postgraduate needs scientific research environment for the 
formation of academic character, it also needs to diversify the methods of personalization training. Personalization research guidance and training must be the joint efforts of supervisor and postgraduate. The supervisor should have a right, reasonable and humanized guidance. And the student should have a subjective and a practice of voluntary. The supervisor not only need to undertake the scientific research teaching and learning of student, but also need to communicate with student about the emotion, thought and life. These tend to be spontaneous guidance and communication, these are also necessary.

\section{The Role Definition of Supervisor and Postgraduate in the Process of Personalization Research Guidance}

Supervisor and postgraduate are the main roles in the process of personalization research guidance and training. It is very important that postgraduate choose a suitable supervisor. Every postgraduate has his own specific research direction. When postgraduates choose a supervisor, they should choose supervisor according to their own special skill and strength, they need to understand the specific research direction and temperament of supervisor. Because the undergraduate's supervisor and postgraduate's supervisor are two different concepts. Supervisor may be an example in your life and reengineering parent of your business.

There are a lot of postgraduates may have enthusiastically devoted to postgraduate school after they selected supervisor. But due to many reasons, they do not finish the work of supervisor's arrangement. For example, they do not familiar with the scientific research tools, the scientific method is not appropriate, learning efficiency is low and lack self-discipline and sensitivity of scientific research. There are many causes of these conditions. Some of them are caused by the supervisor and some are the result of the postgraduate's own situation. Such as the guidance of supervisor about postgraduate is limited to a single teaching and is not for a specific topic. This situation hinders the diversification formation of training mode of postgraduate. This will lead to a postgraduate has no clear scientific research purposes and reasonable scientific research plan. And because the supervisors are usually very busy right now, the communication opportunity between postgraduate and supervisor is usually not as much as you imagine. Especially the current situation is that every supervisor have so many postgraduates. This situation will lead to the communication is not timely between supervisor and postgraduate and they do not know about the present situation of postgraduate research. The postgraduate's guidance is not comprehensive. It is difficult to find problems in the process of scientific research of postgraduate. Even if the postgraduate can have opportunity to discuss with teacher face to face, the supervisor is not familiar on the study content of postgraduate or student are not good at reading and researching the content, the students can't give a clear description about the problems in the research process. So it is hard to give appropriate help to postgraduate.

Based on a variety of reasons, the role definition of postgraduate and supervisor in scientific research work must be accurate. They are no longer simple carrier of teaching and learning. But postgraduate is required to have enough learning initiative, improve the efficiency of research, carefully read and understand the domestic and foreign literature works and have a clear research train of thought. For a supervisor, to take advantage of the rich experiences of past research to guide the students and create a good scientific research environment for them.

\section{The Works of Personalization Cultivation Need Supervisor and Postgraduate to Be Done}

The guidance works of supervisor include: guide the postgraduate study specialized courses and specify keywords such as "personalization" in order to complete the guidance of knowledge learning. Supervisor need to teach literature databases, search engines, etc. to postgraduate, such as CNKI and Google Scholar and so on in order to complete the guidance of ability. Supervisor should teach postgraduate to study and establish consult modestly. The tasks of postgraduate at this stage: learn professional courses and learn words such as "personalization" in order to reserve knowledge. 
Postgraduate should study how to use literature databases and search engines such as precise search as to meet the requirement of ability training. Postgraduate should study hard, strict oneself and establish a good scientific literacy. Figure 1 is the works of personalization cultivation of supervisor and postgraduate.

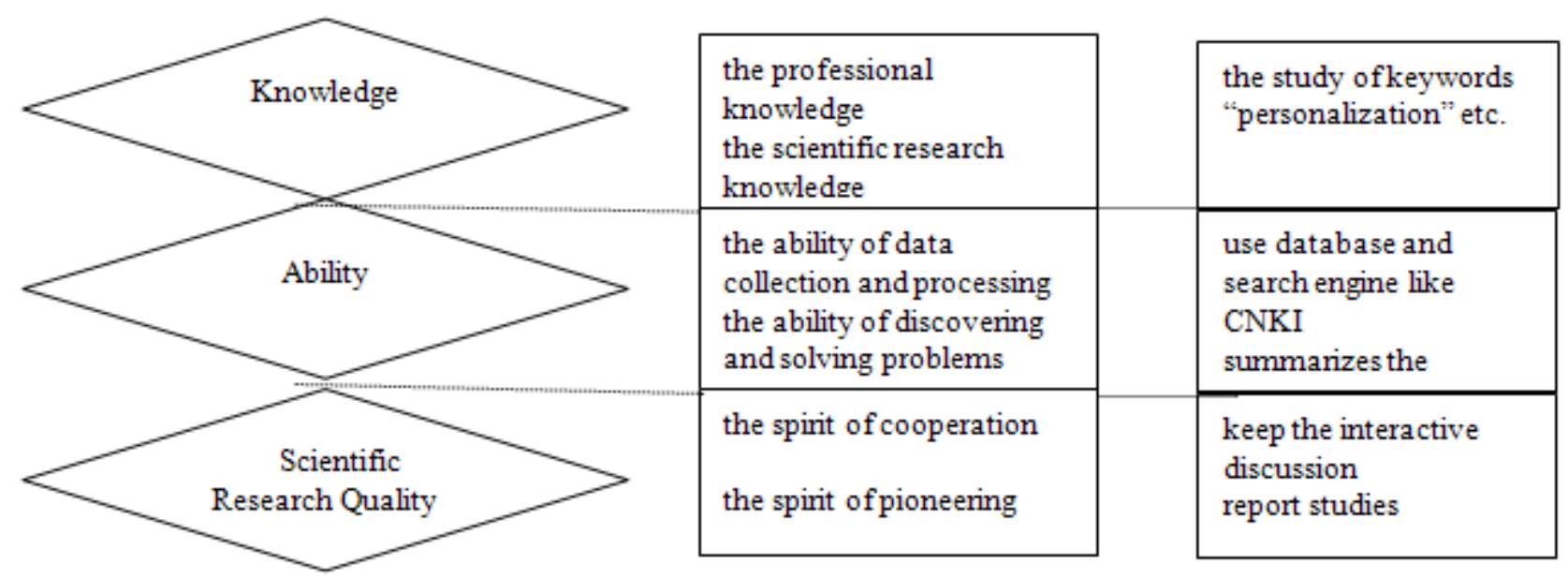

Figure 1 Works of Personalization Cultivation of Supervisor and Postgraduate

\section{The Personalization Cultivation Measures of Postgraduate}

A good quality of postgraduate is the embodiment of scientific research ability under the premise of scientific research needs of the individual. According to the given research direction and key words, postgraduate obtain knowledge or scientific information.

In the process of scientific research, postgraduates manages their own personal knowledge and encourages individuals have upward spiral of tacit knowledge and explicit knowledge formation of transformation between each other under the guidance of tutor step by step. The postgraduate not only can increase the number of individual scientific knowledge but also can improve personal quality of scientific knowledge. To help postgraduate gradually formed the individual system of scientific knowledge. So how to do this? This need the joint efforts of postgraduate and supervisor from the following aspects:

In research activities of postgraduate, supervisor should change ideas, strengthen the awareness of the personal cultivation and break the simplification cultivation model. Supervisor should train the student's ability about his own field. And the supervisor should pay attention to communicate with the postgraduate in order to find problems in a timely manner. The communion and guidance include course and research guidance, it also include the guidance way of thinking and academic communication skills. Supervisor actively support postgraduate for meetings, seminars, training courses, etc. It is a great significance to improve study interest of postgraduate.

The supervisor should give full consideration on the backgrounds, interests, hobbies, IQ and EQ etc. of postgraduate and make full use of different individuals to optimum combination, emphasize professional ability on the basis of the ability of diversification, individuation and cultivate the academic innovation team unity and cooperation. The progress of postgraduate is from the learning process. In that case, unity between postgraduates seem to be very important. And in the process of scientific research, postgraduates rely on the search tool for required information, access and organize scientific research efficiency. But the scientific research data may not fully meet the needs of the scientific research. The scientific research data provided by elder sister and supervisor is more targeted and practical. The data is a great help for postgraduate to enhance the efficiency of scientific research. So the usage of group meeting is a regular basis. To strengthen the team education and management concept and strengthen the team culture. It is an important content.

Postgraduate learns the basic professional and theoretical knowledge under the personalization guidance of supervisor. The process of basic theoretical study is given priority to with self-study, pay 
attention to personal knowledge, strengthen the accumulation of personal knowledge and participate in academic discussion.

Postgraduate should have a reasonable planning time. They must pay attention to practice, cultivate individual and brain ability and focus on cultivating their own independence and innovation. Namely, they need find the problem, question and problem solving skills to cultivate independent thinking. The individual personality development and academic innovation should have a close integration. Any postgraduate should try to go beyond his supervisor. On the basic knowledge accumulation, the student may temporarily unable to transcend supervisor, but they should strive to go beyond the supervisor on the innovation ability.

If postgraduate student has a complaint to supervisor, supervisor has to bear the main responsibility. Supervisor should review himself and try his best to correct it. Supervisor creates a harmonious study atmosphere to postgraduate students. Otherwise, this is not a benefit to postgraduate, the teachers also useless.

From the above, the research guidance is from easy to difficult, the thinking is from low level to high level in order to gradually achieve the goal of postgraduate education. The whole training process as shown in figure 2.

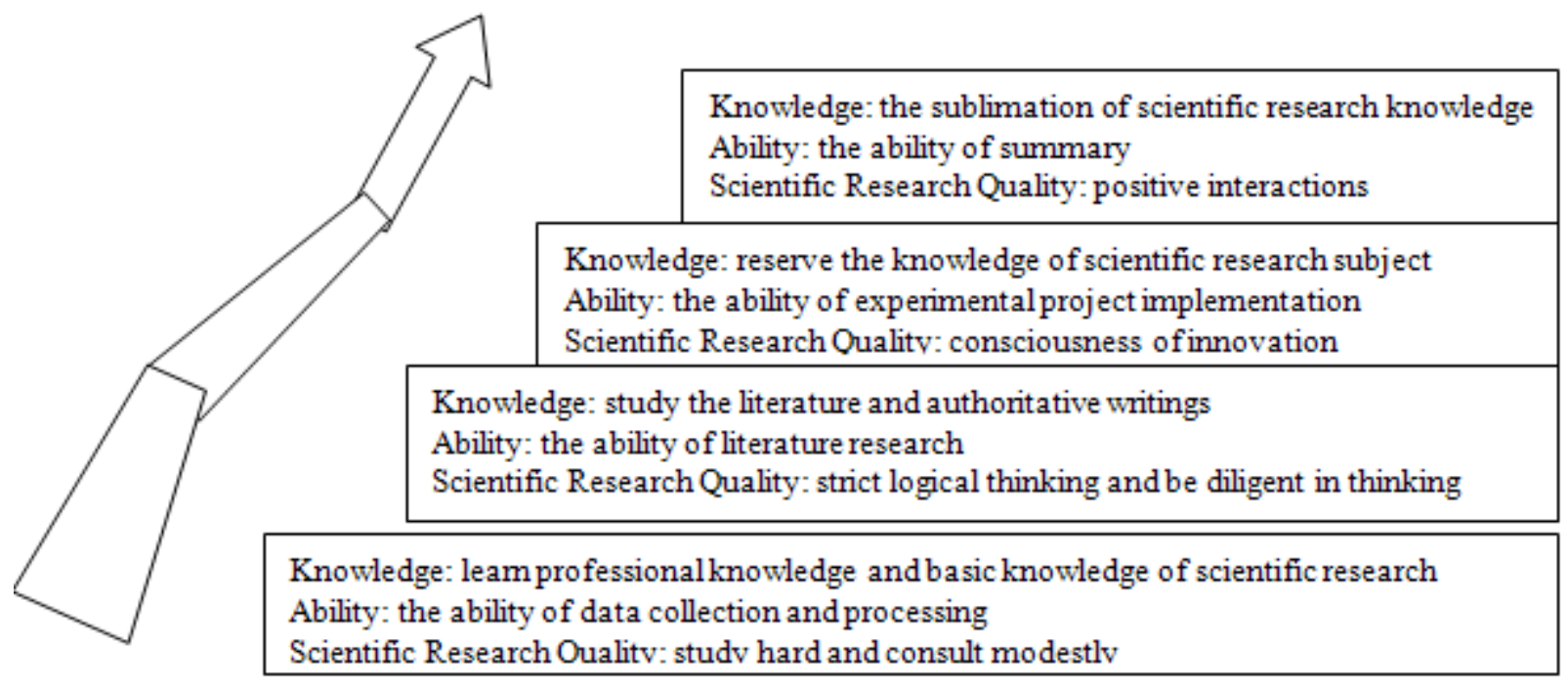

Figure 2 The Whole Training Process of Personalization Cultivation

\section{Conclusion}

The training of supervisor on postgraduate is directly related to the quality of the postgraduate. The education of postgraduate belongs to the individualized education. Each unit and each supervisor bring some personalities of their own in the process of postgraduate education. The supervisor should give vary cultivations for different postgraduates in academic standard, experimental skills, reading and writing ability and speaking ability. It can lead to a postgraduate has a personality in the true sense.

\section{References}

[1] Ashby E. Technology and the academics [M].London: Macmillan

[2] Clark B. The encyclopedia of higher education [C]. Oxford: Pergamon Press

[3] Howard C. Theories of general education [M]. New York: Macmill 